\title{
Fistula-in-ano: How I Do the LIFT Procedure
}

\author{
Sangar P, MBBS, MS ${ }^{1}$, Rojanasakul $\mathrm{A}^{2}$
}

1 Division of Colorectal Surgery, Hospital Selayang, Lebuhraya Selayang-Kepong, Malaysia.

2 Division of Colorectal Surgery, Chulalongkorn University, Bangkok 10330, Thailand.

Key words: Fistula-in-ano, Ligation, Internal

opening

\section{Introduction to LIFT procedure}

This novel technique LIFT (ligation of intersphincteric fistula tract) was developed by Professor Arun Rojanasakul, Colorectal Division Department of Surgery, Chulalongkorn University in Bangkok, Thailand in 2005. LIFT technique is the modified approach through the intersphincteric plane for the treatment of fistula-in-ano. LIFT procedure is based on secure closure of the internal opening and removal of infected cryptoglandular tissue through the intersphincteric approach. Essential steps of the procedure include incision at the intersphincteric groove, identification of the intersphincteric tract, ligation of intersphincteric tract close to the internal opening and removal of intersphincteric tract, scraping out all granulation tissue in the rest of the fistulous tract, and suturing of the defect at the external sphincter muscle [1]. The first report of preliminary healing result from the procedure were $94 \%$ in 2007 [2].

In 1993 Matos et al. described a technique of total anal sphincter preservation in high fistula in ano, which is based on the concept of excision of intersphincteric anal gland infection through the intersphincteric approach [3]. This novel technique was also documented in Corman's textbook of colon and rectal surgery [4]. However, the technique was not widely adopted [5].

Researchers of the procedure agree that the LIFT technique may cause some injury to internal sphincter, but theoretically LIFT causes less trauma of the

Correspondence: P. Sangar, Division of Colorectal Surgery, Hospital Selayang, Lebuhraya Selayang-Kepong, Malaysia

Email: ptsangar@gmail.com

The Sri Lanka Journal of Surgery 2011; 29(2):97-99. internal sphincter than the other fistula operations. Rojanasakul reported the ligation of the internal opening [2]. This represents a significant change from the originally described technique with improved outcomes [6].

\section{Principle of the technique}

1 Ligation of the internal opening close to internal sphincter

2 Excision of the infected anal gland

3 Drainage of the distal tract

4 Preserve the sphincter function

\section{Surgical technique}

Patients are given bowel preparation with enema about 2 hours prior to surgery. The procedure is done under spinal anesthesia and in prone position. Prophylactic antibiotics ciprofloxacin and metronidazole are given.

1. Most of the fistula tract can be identified by palpating an internal opening by rectal examination.

Identify the internal opening by injecting water through the external opening. Do not use probe to identify the internal opening. (Can create false opening)

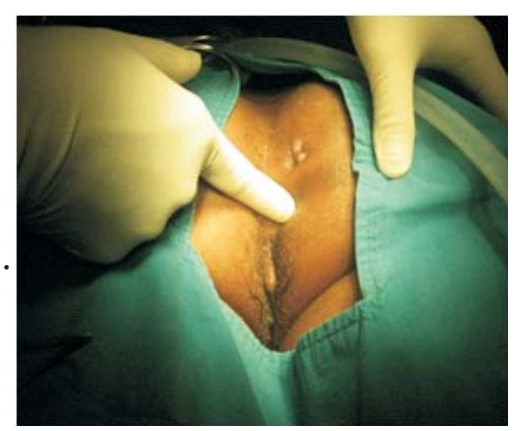

Figure 1. Identifying fistula tract by palpation 


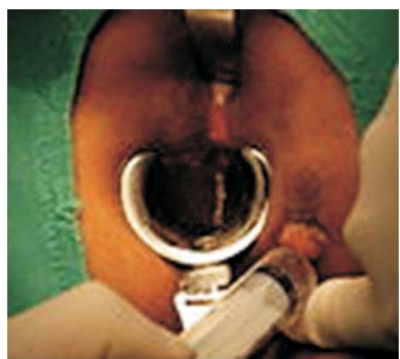

Figure 2. Identify Internal Opening by water injection

2. Incise at intersphincteric groove with diathermy cutting mode and deepen the incision on the same plane using narrow long blade retractor (LIFT retractor). If this is not available some surgeons use Lone-star retractor.

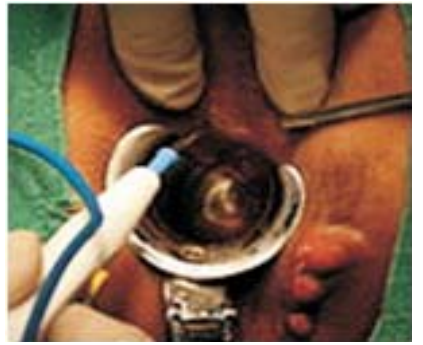

Figure 3. Incision at intersphincteric groove by diathermy

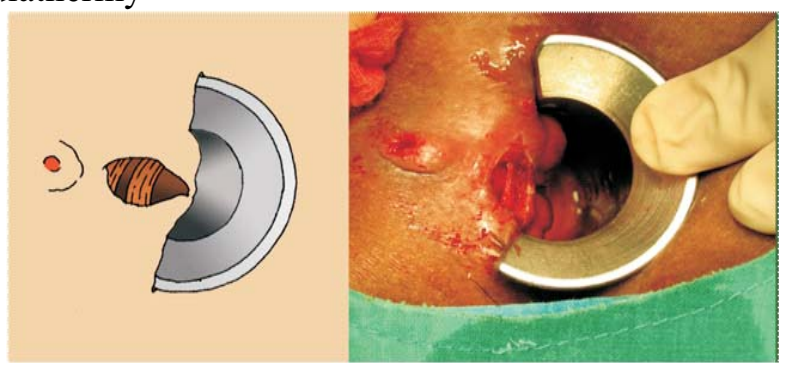

Figure 4. Intersphincteric dissection plane

3. Dissect through intersphincteric plane to find the intersphincteric fistula tract. The tract can be felt as a cord structure. Dissect around the tract using a narrow and small right angle clamp. (The tract does not always cross the incision; sometimes it will be parallel to the incision/ sphincter). Palpation of the dissection plane to identify the tract is very important.

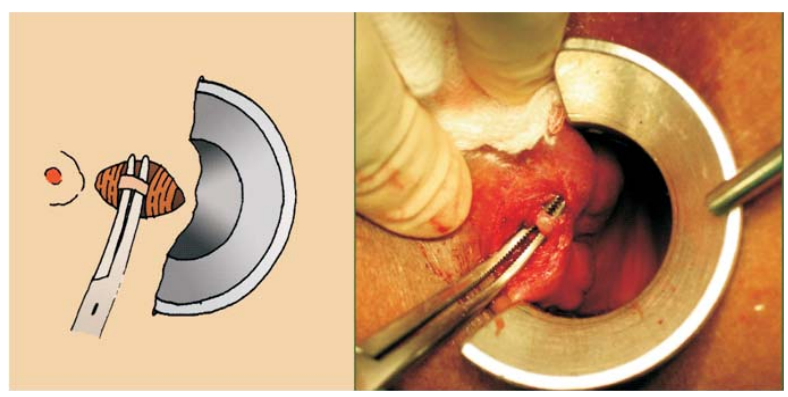

Figure 5. Dissection to find intersphincteric fistula
4.Confirm the tract either by injecting water or passing a probe. Secure suture ligation/transfixing of intersphincteric fistula tract at both sides using $3 / 0$ absorbable suture near to the internal opening (closer to internal sphincter) and another suture at external sphincter defect.

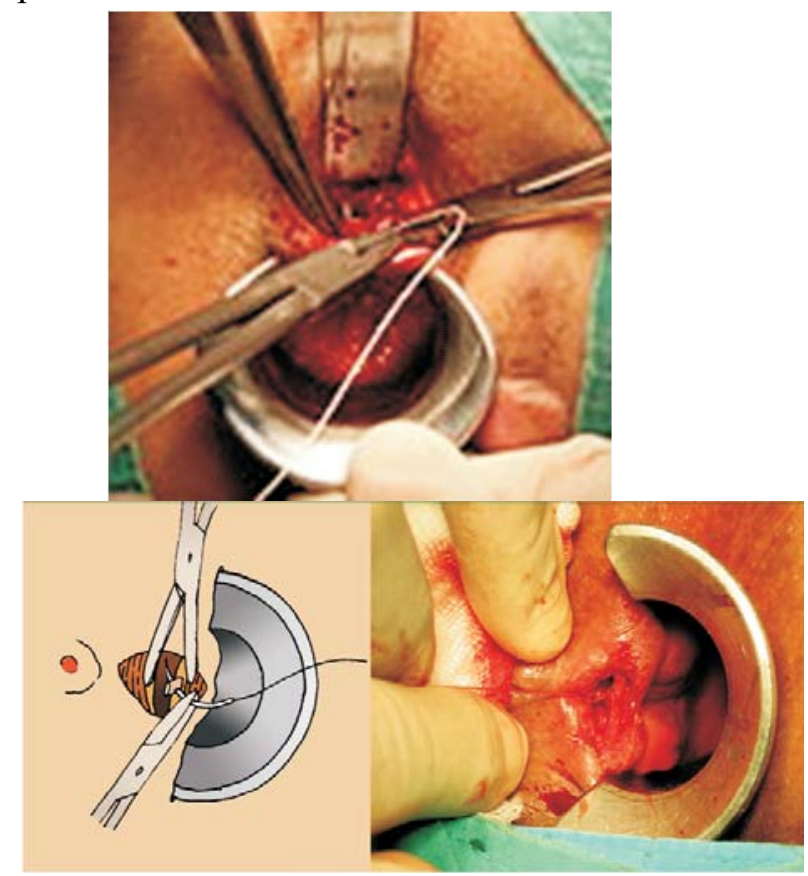

Figure 6. Transfixing the tract near to internal opening/internal sphincter

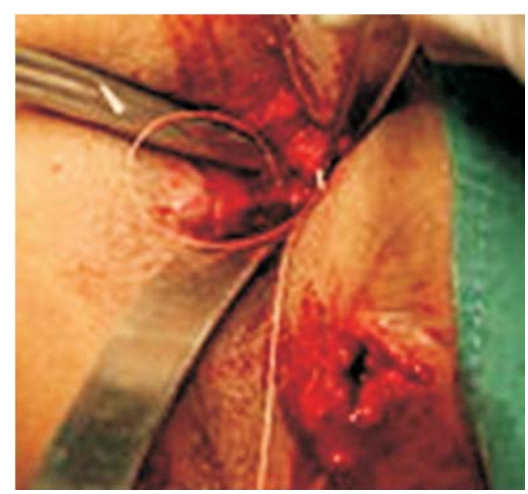

Figure 7. Transfixing fistula tract of external sphincter muscle

5. Remove the fistula tract by excising in between the ligation.

6. Make sure the tract is sutured well by injecting water and as well as by inserting a probe at both openings (internal and external opening).

7. Curette well the fistula tract from external opening 


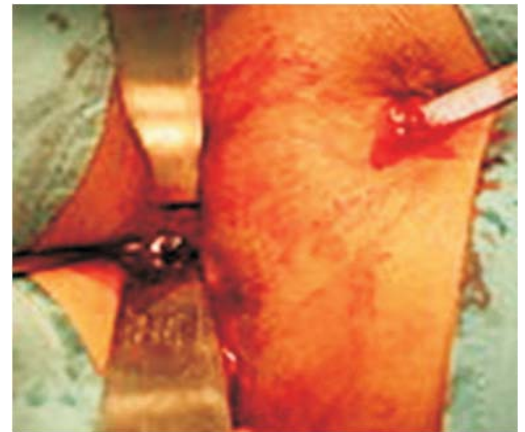

Figure 8. Curetting distal fistula tract from external opening

8.Closure of intersphincteric wound with absorbable suture $3 / 0$ simple interrupted single layer

\section{Discussion}

The advantages of the LIFT technique are 1) anal sphincter sparing, 2) minimal tissue injury resulting in a shorter healing time, 3) small scar, 4) the procedure can be done in previously-operated patients, and lastly 5 ) the procedure will not compromise any need for reoperation in case of recurrence. At the beginning, the authors used LIFT technique only for complex fistulae but since the early results were good, the authors are now using this technique for nearly all fistula-in-ano patients. The major concern was long-term recurrence but with the authors' experience of more than 5 years with this procedure, there are extremely rare of recurrent fistula after primary healing.

The healing rate of fistula is report at approximately 67-94\%. In 2007 Rojanasakul A reported healing rate of 94\% [2]. Shanwani A 2010 [7] and ArmenAboulian 2011 [8] reported primary healing rate of $82 \%$ and $68 \%$ respectively. LIFT procedure is a safe and economical technique with minimal tissue injury and low recurrence rates as well as being easy to perform. The ligation of the intersphincteric fistula tract technique for fistula-in-ano surgery, which aims at total anal sphincter preservation, appears to be both safe with encouraging early outcomes.

The main reasons why there are recurrences after LIFT procedure are failing to identify the internal opening, failing to secure the suture of the internal opening or Slippage of the ligature, not adequate curettage of the distal tract and creating a false tract by forceful probing. This procedure is applicable to all types of fistula. Rojanasakul successfully treated perianal abscesses with fistula using the LIFT procedure as a one step procedure. The authors believe that the LIFT procedure will become the treatment of choice for fistula in ano and also the one step procedure for fistulae with perianal abscesses.

\section{References}

1. Rojanasakul A. LIFT procedure: a simplified technique for fistula-in-ano. Tech Coloproctol. 2009;13(3):237-40.

2. Rojanasakul A, Pattanaarun J, Sahakitrungruang C, Tantiphlachiva K. Total anal sphincter saving technique for fistula-inano; the ligation of intersphincteric fistula tract. J Med Assoc Thai. 2007; 90(3):581-6.

3. Matos D, Lunniss PJ, Phillips RKS Total sphincter conservation in high fistula in ano: results of a new approach. Br J Surg. 1993;80:802-804

4. Corman M L (2004) Anal Fistula. In: Colon and Rectal Surgery. 5th edn. Lippincott Williams \& Wilkins, pp 316

5. Lunnis PJ, Invited comment: LIFT procedure: a simplified technique for fistula in ano. Tech Coloproctol 2009; 13:241-242

6. Rojanasakul A. Comments to the invited comment "LIFT procedure: a simplified technique for fistula in ano" by P. J. Lunniss. Tech Coloproctol. 2010; 14(1):53-4.

7. Shanwani A, Nor AM, Amri N Ligation of the intersphincteric fistula tract (LIFT): a sphinctersaving technique for fistula-in-ano. Dis Colon Rectum. $2010 ; 53(1): 39-42$.

8. ArmenAboulian, Amy H. Kaji, Ravin R. Kumar. Early Result of Ligation of the IntersphinctericFistula Tract for Fistula-in-Ano. Dis Colon Rectum. 2011vol 54:3 (2011) 